\title{
Ayurveda: Between Religion, Spirituality, and Medicine
}

\author{
C. Kessler, ${ }^{1}$ M. Wischnewsky, ${ }^{2}$ A. Michalsen, ${ }^{1}$ C. Eisenmann, ${ }^{3}$ and J. Melzer $^{4,5}$ \\ ${ }^{1}$ Department of Internal and Complementary Medicine, Immanuel Hospital and Institute of Social Medicine, Epidemiology \& \\ Health Economics, Charité-University Medical Center, Research Coordination, Königstraße 63, 14109 Berlin, Germany \\ 2 eScience Center, University of Bremen, Universitätsallee, 28359 Bremen, Germany \\ ${ }^{3}$ Graduate School in History and Sociology, Bielefeld University, 33615 Bielefeld, Germany \\ ${ }^{4}$ Institute of Complementary Medicine, University Hospital Zurich, 8001 Zurich, Switzerland \\ ${ }^{5}$ Department for Psychiatry, Psychotherapy and Psychosomatics, Königin-Elisabeth-Herzberge Hospital, 10365 Berlin, Germany
}

Correspondence should be addressed to C. Kessler; kessler.christian@gmail.com

Received 6 June 2013; Revised 5 September 2013; Accepted 3 October 2013

Academic Editor: Arndt Büssing

Copyright (C) 2013 C. Kessler et al. This is an open access article distributed under the Creative Commons Attribution License, which permits unrestricted use, distribution, and reproduction in any medium, provided the original work is properly cited.

\begin{abstract}
Ayurveda is playing a growing part in Europe. Questions regarding the role of religion and spirituality within Ayurveda are discussed widely. Yet, there is little data on the influence of religious and spiritual aspects on its European diffusion. Methods. A survey was conducted with a new questionnaire. It was analysed by calculating frequency variables and testing differences in distributions with the $\chi^{2}$-Test. Principal Component Analyses with Varimax Rotation were performed. Results. 140 questionnaires were analysed. Researchers found that individual religious and spiritual backgrounds influence attitudes and expectations towards Ayurveda. Statistical relationships were found between religious/spiritual backgrounds and decisions to offer/access Ayurveda. Accessing Ayurveda did not exclude the simultaneous use of modern medicine and CAM. From the majority's perspective Ayurveda is simultaneously a science, medicine, and a spiritual approach. Conclusion. Ayurveda seems to be able to satisfy the individual needs of therapists and patients, despite worldview differences. Ayurvedic concepts are based on anthropologic assumptions including different levels of existence in healing approaches. Thereby, Ayurveda can be seen in accordance with the prerequisites for a Whole Medical System. As a result of this, intimate and individual therapist-patient relationships can emerge. Larger surveys involving bigger participant numbers with fully validated questionnaires are warranted to support these results.
\end{abstract}

\section{Introduction}

Ayurveda, a form of Traditional Indian Medicine (TIM), literally translates from Sanskrit to "knowledge of life" or more precisely "systematic knowledge of the lifespan" [1]. Ayurveda is a Whole System of Medicine (WMS) [2-5]. In its South Asian countries of origin it has been practiced for more than 2000 years in an unbroken tradition and is thus one of the oldest WMS of mankind [6]. Ayurveda is fully recognized by the World Health Organization (WHO) as a medical science analogous to Traditional Chinese Medicine (TCM) and has amassed an enormous wealth of empirical healing knowledge. (Proto)scientific concepts have had a firm place in mainstream Ayurvedic medicine ever since around the beginning of the common era with the emergence of the "classic texts" (e.g., Caraka Samhita [7, 8]) and are centered around designated disciplines of logic and methodology
[9]. In India and some neighboring countries, Ayurvedic medicine is officially and legally recognized as on par with conventional medicine. It is used in an area with more than 1.4 billion people as a broad system of medicine $[10,11]$. The importance of Ayurveda in modern South Asian health care setups is reflected by the following figures: in India alone above 400,000 registered Ayurvedic physicians practice Ayurveda [12] and there are more than 250 universities and colleges where Ayurvedic medicine is systematically taught as a 4-6-year university degree program [13]. In its diagnostic and therapeutic approaches Ayurveda is steeped in the principles of salutogenesis [14] Primary, secondary, and tertiary prevention, patient self-empowerment, and self-efficacy play crucial roles in the holistic and multidimensional Ayurvedic approach to healing [15]. Ayurveda not only is a WMS but also incorporates eclectic philosophies of life that have helped to shape complex theories about health 
and disease over more than three millennia, including philosophical, epistemological, and spiritual dimensions. For example, Ayurveda postulates a paradigmatic harmony of physiological, psychological, social, and environmental factors of the human microcosm and the universal macrocosm $[16,17]$.

In addition to its key role in Asian health care systems, it is playing a growing role in Complementary and Alternative Medicine (CAM), especially in integrative settings in Europe and North America. For instance, in Germany, Austria, and Switzerland Ayurveda is one of the fastest growing CAM methods [18]. An internet search for "Ayurveda" yields $>7,400,000$ entries in Google [19]. In 2011 the establishment of the German Medical Doctors Association of Ayurvedic Medicine (DÄGAM) took place [20]. In several training institutions throughout Germany professional development and training opportunities certified by various state-level German Medical Doctors' Associations are being offered (e.g., in Bavaria, Berlin, North Rhine-Westphalia, SchleswigHolstein, Hessen, Hamburg, and Rhineland-Palatinate). Yet there is no national certificate for Ayurveda. Important areas of discussion surrounding the character of Ayurveda include (a) its underlying core concepts for diagnosis and therapy, (b) ultimate therapeutic aims, and (c) demarcation from other South Asian traditional medical systems (e.g., Siddha, UnaniTibb) and modern western medicine and remain largely unanswered [17]. Inquiries regarding the importance of religion and spirituality within medical contexts have been posed repeatedly in Indology, Sociology, Anthropology, Religious Studies, and Medical Sciences [18, 21, 22]. Whole Medical Systems (WMS) are by definition complete and coherent systems of medical theory and practice that have evolved and continue evolving, in different regions, cultures, and time periods around the globe. They have evolved relatively independent of modern western medicine, for example, Traditional European Medicine (anthroposophy, homeopathy, and naturopathy), Traditional Chinese Medicine (TCM), Tibetan Medicine, or Arabian systems of medicine [23-29].

Concerning Ayurveda, two main opposing positions can be observed: [16] (a) supporters of "scientific" Ayurveda state that it has always been an empirical medical system in which religious and spiritual speculations are mere interpolations, alien to the system, or (b) supporters of "traditional" Ayurveda state that religious and spiritual elements have always been integral components of Ayurveda as a WMS. These positions are, however, not mutually exclusive.

There is growing acceptance and demand for Ayurveda in western countries and there are currently more than 2500 online publications on Ayurvedic therapies in PubMed [30] and greater than 52,000 referenced Ayurveda research articles in the Indian digital database DHARA (Digital Helpline for Ayurveda Research Articles) [31]. It is hypothesized that spirituality might be a main attractor for the increasing popularity of Ayurveda [32]; however, there is still little scientific evidence regarding the influence of religious and spiritual elements on the diffusion and implementation of modern hybrid forms of Ayurveda [33-35].

This is striking because spirituality has already entered discussions in neurobiology [36] and most of all quality of life (QoL) research [37], especially in chronic diseases [38-44]. However, cultural and spiritual attractors of nonwestern CAM have been discussed in recent years [45, 46] and are beginning to be researched [47, 48]. The rather late awareness of spiritual aspects in CAM might be due to the impact that the methodology of Evidence-based Medicine (EbM) had on the medical system as such and in particular on research initiatives in CAM. More recently, after CAM research has managed to close some evidence gaps, researchers have become aware of the necessity to conduct research focused not only on specific evidence but also on unspecific or contextual or patient-centred aspects (related to CAM) [49-52]. This is by no means in opposition to EbM because one of its founders defined EbM as the integration of (a) the best research evidence with (b) clinical expertise and (c) patient values [53]. However, clinical research had focused predominantly on the two former aspects until recently.

In order to explore the general role of religion and spirituality specifically within the field of Ayurveda, a new questionnaire was developed. While existing questionnaires, for example, the Spiritual Perspective Scale [54, 55], the S-PRIT [56], the FACIT-Sp [57], the Spiritual Well-Being Scale [58], Aspects of Spirituality [59], the SpREUK [60], the Health and Religious Congruency Scale [61] and others [62-68] would be useful for further analysis, the objective of this pilot survey was to focus on the specificities of the complex field of Ayurveda in a western setting, leaving the definition of spirituality as open as possible. Spirituality and religion were thereby not used as analytical but as emic (ethno)categories [69-71]. This questionnaire was distributed among patients accessing and therapists offering Ayurveda in German-speaking countries.

1.1. Hypothesis. To shed some light on the influence and meaning of religious and spiritual aspects on the diffusion and implementation of Ayurvedic practices in Europe the following hypotheses were formulated to the survey a priori.

(i) Hypothesis 1. Participants who apply Ayurveda as a therapist or receive Ayurveda as a therapy are religious and/or spiritual. Ayurveda is perceived as a healhcare approach which incorporates religious and spiritual demands.

(ii) Hypothesis 2. For patients and therapists, principles of Ayurveda and modern science are not in conflict. Concepts of religion, spirituality, and science can be integrated.

(iii) Hypothesis 3. Elements from South Asian cultures, religions, and philosophies are supposed to have an effect on the results of Ayurvedic therapies.

(iv) Hypothesis 4. Women are more open to religious and spiritual aspects in the case of Ayurvedic therapists and patients than men.

\section{Methods}

2.1. Survey. To test these hypotheses a questionnaire was developed and distributed among patients and therapists in 
western Ayurvedic health care settings in Frankfurt a. M., Birstein, Passau, Bremen, Hanover, Zurich, and Vienna. These settings included (a) private Ayurvedic practices, (b) the International Ayurveda Symposium in Birstein, and (c) direct contacts of the corresponding author. To rule out any potential selection bias of the participants, questionnaires were given to the first sequential 300 eligible persons contacted.

To be included participants had to be $\geq 18$ years of age. Patient participants had to have had $\geq 1$ experience with Ayurvedic therapies and therapist participants had to have had at least one course of institutionalized Ayurvedic training and had to offer Ayurvedic therapies or have a plan to do so at the time of inclusion (details about the individual training duration were not further assessed).

Patients were excluded if they suffered from a life threatening disease, in order to avoid systematic bias/confounders due to a "last exit mentality" which can influence the overall compliance with respect to their choice of therapies and therapists.

The survey with anonymized questionnaires, part of a master thesis for the corresponding author, was performed at the Institute for Indology and Tibetology, Philosophical Faculty, University of Göttingen, Germany. Of note this is not a clinical study, and according to university procedures therefore no ethical approval was mandatory and informed consent, anonymized questionnaires, and respect of data privacy were sufficient.

2.2. Construction of the Questionnaire. Firstly, a preliminary questionnaire considering content validity, internal consistency, criterion validity, construct validity, and reproducibility was developed [72].

The items for the preliminary questionnaire version were derived from three sources: (1) exploratory interviews with expert representatives, (2) as discussed in the research literature, and (3) items inspired by existing questionnaires in the field (e.g., "Aspects of Spirituality," see above). This preliminary version of the questionnaire was pretested with 10 test persons accustomed to filling out questionnaires, to gain information on reliability and validity aspects. The questionnaire was then modified based on the received feedback and reexamined. It was then modified and approved by expert representatives and scholars from various disciplines (Medicine, Indology, Religious Sciences, Informatics, and Sociology). This resulted in a final version of the questionnaire to be distributed to the target group in its finalized version. Therefore the underlying questionnaire might be regarded as a "standard" questionnaire in the sense of Olsen [73]. A validated questionnaire in the traditional sense was not possible, since we could not compare this instrument against a gold standard, as such a gold standard for Ayurveda as a Whole Medical System this context does not yet exist [58].

The final version of the questionnaire included a section for sociodemographic baseline data and 50 questionnaire items. The majority of the items are scored on a 5-point Likert scale ranging from "total" disagreement to "total" agreement
(0-4) or on a 3-point Likert scale (i.e., "yes," "no," and "do not know"). In order to obviate the problem of acquiescence bias, we designed a scale with balanced keying (an equal number of positive and negative statements), while possible distortions through central tendency and social desirability are more difficult to control.

2.3. Statistics and Validation. All returned questionnaires underwent statistical analysis. For descriptive statistics each item was analyzed separately and in some cases item responses were summed to create a score for a group of items. The frequencies of the various variables were calculated. Differences in frequency distributions were tested with the $\chi^{2}$ Test. Principal Component Analyses with Varimax Rotation and Kaiser Normalization were used to represent the main structural features of the multivariate data set by a smaller number of attributes. This is achieved by transforming data from the original coordinate system (i.e., spanned by the original attributes) into a different coordinate system where the variables are linearly independent. The factor loading, a standardized scoring coefficient, was used to determine the contribution of a variable to a particular factor. Variables with rotated absolute factor values $>0.5$ (or $<-0.5$ ) for a particular factor were considered significant contributors for that factor (see Table 3. The 12 variables are replaced by 4 factors: for example, the variables "Ayurveda = Spirituality?", "Ayurveda = Philosophical system?", and "Ayurveda = Way of life?" have rotated absolute factor values $>0.5$ for factor 1 , which expresses a strong correlation between these variables; all other variables have factor values $\leq 0.5$ or $\geq-0.5$ with respect to factor 1; therefore they do not significantly contribute to this factor). Negative rotated absolute factor values express inverse correlations. We used 10 or more test persons per item in connection with multivariate analyses. Ten test persons per 1 item is a well-known rule of thumb for the number of instances (data sets) in connection with knowledge discovery processes, that is, multivariate analyses. Based on reliability analyses inner consistencies and discriminatory power were tested. A significance level of $P<0.05$ was taken as a basis. Calculations were performed with NCSS (version 2007) and SPSS (version 19).

The validation of questionnaires in general is based on methods of the classical test theory and factor analyses for the design of questionnaire items. Factor analysis was one of the central methods for the evaluation of this questionnaire. It serves for the grouping of parameters and for the partial validation of this questionnaire. The a priori allocation of different subject areas was tested by factor analyses. For each subject area a factor analysis was calculated to find out whether the chosen subject area captures the construct or whether the existence of several factors hints at the existence of different subconstructs. We used the Principal Components Analysis as extraction method. As a support for finding out the number of factors of a subject area (=number of subconstructs) we used the Kaiser-Guttman criterion [74] (number of factors to be extracted $=$ number of the factors with eigenvalue $>1$ ) and the scree test of the eigenvalue course [75]. 
TABLE 1: Sociodemographic data.

\begin{tabular}{|c|c|c|c|c|}
\hline Parameters & Therapists & Patients & Total & $P$ value \\
\hline Number of patients (\%) & $70(50.0 \%)$ & $70(50.0 \%)$ & $140(100 \%)$ & \\
\hline Age & & & & 0.296 \\
\hline$<30$ & $6(11.6 \%)$ & $2(2.9 \%)$ & $10(7.2 \%)$ & \\
\hline $30-50$ & $42(60.9 \%)$ & $50(71.4 \%)$ & $92(66.2 \%)$ & \\
\hline$>50$ & $19(27.5 \%)$ & $18(25.7 \%)$ & $37(26.6 \%)$ & \\
\hline Gender & & & & 0.693 \\
\hline Male & $18(25.7 \%)$ & $16(22.9 \%)$ & $34(24.3 \%)$ & \\
\hline Female & $52(74.3 \%)$ & $54(77.1 \%)$ & $106(75.7 \%)$ & \\
\hline Education & & & & 0.923 \\
\hline Secondary school & $5(7.1 \%)$ & $5(7.1 \%)$ & $10(7.1 \%)$ & \\
\hline Junior high school & $16(22.9 \%)$ & $19(27.1 \%)$ & $35(25.0 \%)$ & \\
\hline High school & $13(18.6 \%)$ & $11(15.7 \%)$ & $24(17.1 \%)$ & \\
\hline University/college & $31(44.3 \%)$ & $28(40.0 \%)$ & $59(42.1 \%)$ & \\
\hline Others & $5(7.1 \%)$ & $7(10.0 \%)$ & $12(8.6 \%)$ & \\
\hline Actual profession & & & & $<0.001$ \\
\hline Medical doctor & $24(34.8 \%)$ & $9(12.9 \%)$ & $33(23.7 \%)$ & \\
\hline Alternative practitioner & $5(7.2 \%)$ & $0(0 \%)$ & $5(3.6 \%)$ & \\
\hline Ayurveda therapist & $22(31.9 \%)$ & $11(15.7 \%)$ & $33(23.7 \%)$ & \\
\hline Yoga instructor & $3(4.3 \%)$ & $1(1.4 \%)$ & $4(2.9 \%)$ & \\
\hline Psychologist & $1(1.4 \%)$ & $0(0 \%)$ & $1(0.7 \%)$ & \\
\hline Medical associated profession & $3(4.3 \%)$ & $3(4.3 \%)$ & $6(4.3 \%)$ & \\
\hline Others & $11(15.9 \%)$ & $46(65.7 \%)$ & $57(41.0 \%)$ & \\
\hline Income ( $€$ per month) & & & & 0.233 \\
\hline$<1000$ & $17(25.0 \%)$ & $7(10.3 \%)$ & $24(17.6 \%)$ & \\
\hline $1000-1500$ & $11(16.2 \%)$ & $11(16.2 \%)$ & $22(16.2 \%)$ & \\
\hline $1500-2000$ & $9(13.2 \%)$ & $12(17.6 \%)$ & $21(15.4 \%)$ & \\
\hline $2000-2500$ & $7(10.3 \%)$ & $6(8.8 \%)$ & $13(9.6 \%)$ & \\
\hline$>2500$ & $16(23.5 \%)$ & $17(25.0 \%)$ & $33(24.3 \%)$ & \\
\hline Unknown & $8(11.8 \%)$ & $15(22.1 \%)$ & $23(16.9 \%)$ & \\
\hline Number of children & & & & 0.653 \\
\hline 0 & $28(40.0 \%)$ & $34(49.3 \%)$ & $62(44.6 \%)$ & \\
\hline 1 & $11(15.7 \%)$ & $11(15.9 \%)$ & $22(15.8 \%)$ & \\
\hline$\geq 2$ & $31(44.3 \%)$ & $24(34.7 \%)$ & $55(39.6 \%)$ & \\
\hline Location (number of inhabitants) & & & & 0.806 \\
\hline$<5000$ & $10(14.3 \%)$ & $8(11.6 \%)$ & $18(12.9 \%)$ & \\
\hline $5000-50000$ & $18(25.7 \%)$ & $17(24.6 \%)$ & $35(25.2 \%)$ & \\
\hline $50000-100000$ & $11(15.7 \%)$ & $8(11.6 \%)$ & $19(13.7 \%)$ & \\
\hline$>100000$ & $29(41.4 \%)$ & $35(50.7 \%)$ & $64(46.0 \%)$ & \\
\hline Unknown & $2(2.9 \%)$ & $1(1.4 \%)$ & $3(2.2 \%)$ & \\
\hline
\end{tabular}

\section{Results}

Overall 300 questionnaires were distributed (120 in private practices, 130 at the International Ayurveda Symposium in Birstein, and 70 through direct contacts of the corresponding author). 140 completed questionnaires were returned, exactly (and coincidently) 70 from patients and 70 from therapists (53 from private practices, 45 from the 7 th International Ayurveda Symposium in Birstein, and 42 from professional contacts of the corresponding author). Following the sociodemographic background, the results of the questionnaire will be summarized in order of the respective hypotheses.
Parts of the results are presented as pooled data from patients and therapists wherever there is no significant difference between the two groups.

\subsection{Baseline Data}

Sociodemographic. Among the participants of the survey a significant difference in sociodemographic data was only found for profession but not for age, gender, education, income, or location (Table 1).

Other. Four survey participants (all patients) had only 1 experience with Ayurveda at the time of the interview. 
TABLE 2: Characterization of Ayurveda by therapists and patients.

\begin{tabular}{lccccc}
\hline Ayurveda is a... & Therapists & $\begin{array}{c}\text { Patients } \\
N(\%)\end{array}$ & Total & Total number of valid cases \\
\hline Health doctrine & $67(100 \%)$ & $69(100 \%)$ & $136(100 \%)$ & 136 \\
Medical system & $66(97.1 \%)$ & $57(91.9 \%)$ & $123(94.6 \%)$ & 130 & 114 \\
Philosophical system & $54(87.1 \%)$ & $37(71.2 \%)$ & $91(79.8 \%)$ & 122 & 102 \\
Science & $60(92.3 \%)$ & $53(93.0 \%)$ & $113(92.6 \%)$ & 97 & 0.196 \\
Religious doctrine & $16(30.8 \%)$ & $18(36.0 \%)$ & $34(33.3 \%)$ & 118 & 1035 \\
Religion & $7(14.0 \%)$ & $4(8.5 \%)$ & $86(72.9 \%)$ & $11.3 \%)$ & 0.575 \\
Spirituality & $47(75.8 \%)$ & $39(69.6 \%)$ & $12(11.8 \%)$ & 104 & 0.394 \\
Esoterism & $7(13.7 \%)$ & $5(9.8 \%)$ & $73(70.2 \%)$ & 0.539 \\
Philosophy of life & $39(73.6 \%)$ & $34(66.7 \%)$ & & 0.441 \\
\hline
\end{tabular}

The individual training range from the surveyed therapists ranges widely from below three months to a 4-6-year academic Ayurvedic training in South Asia.

3.2. Findings Related to Hypothesis 1. $65 \%$ of the respondents belong to a religion and describe themselves as religious/spiritual. $81 \%$ describe the influence of religion and spirituality on their daily life as important. $73 \%$ consider Ayurveda to be a form of spirituality (76\% of therapists, $57 \%$ of patients), but only $11 \%$ think of Ayurveda as a religion (findings not shown).

Traditional Christian values and beliefs are confirmed (e.g., $77 \%$ believe in God), but in addition a majority also believe in non-Christian concepts (karma 66\%, rebirth 64\%, and transmigration of the soul $58 \%$ ). Patients adhere more to traditional Christian values and beliefs than therapists; for instance, a belief in a Christian god can be observed among $83 \%$ of patients and $71 \%$ of therapists $(P=0.107)$. Yet at the same time therapists adhere more to traditional South Asian values and beliefs: $84 \%$ of therapists and $59 \%$ of patients believe in karma ( $P=0.003), 74 \%$ of therapists and $54 \%$ of patients believe in rebirth $(P=0.009)$. A general affinity for South Asian religions is noticeable. $71 \%$ share a fascination for Buddhism and $38 \%$ for Hinduism (no significant differences between patients and therapists). $49 \%$ find Christian religions to be lacking mystical elements that can be better served by Buddhism or Hinduism. 43\% think that South Asian religions can respond better to prevailing problems than western religions. $60 \%$ of all respondents believe that disease is conditioned through karma while $95 \%$ are convinced that faith and belief are important prerequisites for healing. Still $81 \%$ think that divine power and karma (66\%) are important healing factors and $67 \%$ have prayed (74\% among therapists, $61 \%$ among patients $(P=0.138))$.

Three "groups of believers" can be delineated: (1) a group, whose members simultaneously believe in karma, nirvana, a universal soul, transmigration of the soul, and rebirth; (2) a group with a statistical relation between believing in the god, the devil, and angels; and (3) a group, characterized by simultaneous beliefs in a metaphysical sense of life and $\operatorname{god}(\mathrm{s})$.

The most prominent aspects of traditional Christian spirituality and of South Asian spirituality derived from this data are (1) belief in God (Bonferroni adjusted $P$ value (adj. $P) P<0.001$ ), (2) belief in divine beings (adj. $P<0.001$ ), and (3) belief in rebirth (adj. $P=0.010$ ). Only 3 patients and 1 therapist declared themselves as nonreligious. Nevertheless 3 of these believe in a cosmic soul, karma, rebirth, sense of life, divine beings, or transgression of soul, so only 1 "nonbeliever" remains in total.

3.3. Findings Related to Hypothesis 2. $100 \%$ of all participants (valid cases) consider Ayurveda to be a health doctrine, 95\% to be a medical system, and $93 \%$ to be a science. $80 \%$ relate it to a philosophical system (87\% among therapists, 55\% among patients $(P=0.035)$ ), while $73 \%$ of all respondents consider Ayurveda to be a form of spirituality. However, only $11 \%$ consider Ayurveda to be a religion (Table 2). 76\% believe that Ayurvedic therapists have functions related to spiritual guidance (therapists $79 \%$, patients $73 \%(P=0.641))$. Though a majority (93\%) of respondents consider Ayurveda to be a science, only $28 \%$ think that Ayurveda is scientific in a modern western sense. $59 \%$ see Ayurveda as a complement to modern medicine, while more than $25 \%$ think that it should be used exclusively. Only about 30\% state that Ayurveda should be analysed through scientific studies (therapists $29 \%$, patients $32 \%(P=0.260))$. However, $76 \%$ think that medical aspects of Ayurveda are more important than religious and/or spiritual aspects (therapists $74 \%$, patients $78 \%(P=0.635))$. $25 \%$ consider schooling in modern medicine to be a negative influence on the religious and spiritual characteristics of the Ayurvedic therapist.

The 12 variables in Table 3 could be reduced to 4 different factors: (1) factor 1 comprises the variables designating Ayurveda to have a spiritual nature, to be a philosophical system, and to be a way of life; (2) factor 2 accounts for the correlation that it is a religion, a religious doctrine, and esoteric; (3) factor 3 sees it as a medical system, a science, and a philosophy of life; and (4) factor 4 pulls together the perceptions of Ayurveda as a complement to modern medicine and as scientific in a modern western sense (Table 3 ).

3.4. Findings Related to Hypothesis 3. $65 \%$ of respondents believe that Ayurveda can be expediently practiced in the West, detached from South Asian culture, religion, and philosophy. At the same time $66 \%$ believe that Ayurvedic 
TABLE 3: Factor analysis of participants' characterization of Ayurveda.

\begin{tabular}{|c|c|c|c|c|}
\hline \multirow{2}{*}{ Variables } & \multicolumn{4}{|c|}{ Factors } \\
\hline & 1 & 2 & 3 & 4 \\
\hline Ayurveda = spirituality? & 0.8 & & & \\
\hline Ayurveda $=$ philosophical system $?$ & 0.8 & & & \\
\hline Ayurveda = way of life? & 0.7 & & & \\
\hline Ayurveda = religion $?$ & & 0.8 & & \\
\hline Ayurveda $=$ religious doctrine $?$ & & 0.7 & & \\
\hline Ayurveda $=$ esoterism $?$ & & 0.7 & & \\
\hline Ayurveda $=$ medical system $?$ & & & 0.8 & \\
\hline Ayurveda $=$ science $?$ & & & 0.6 & \\
\hline Ayurveda $=$ philosophy of life? & & & 0.6 & \\
\hline Ayurveda $=$ complement to modern medicine $?$ & & & & 0.8 \\
\hline Ayurveda $=$ closed medical system, which does not require a combination with western medicine? & & & & -0.7 \\
\hline Ayurveda $=$ scientific in a modern western sense? & & & & 0.5 \\
\hline
\end{tabular}

experts from South Asia should participate in teaching the medical system (which actually occurred in $87 \%$ of the cases). Almost $50 \%$ of the participants are convinced that Ayurvedic schooling should include at least one study visit to South Asia. 71\% have the opinion that Ayurveda therapists should educate their patients in fundamental concepts of Ayurveda during the therapy. 50\% of the interviewees think that basic knowledge about South Asian culture is important for patients. $61 \%$ agree with the statement that Ayurvedic therapists should sympathize with South Asian culture, religion, and philosophy, while $67 \%$ feel attached to South Asian culture, religion, and philosophy (80\% among therapists, $55 \%$ among patients $(P=0.003)) .70 \%$ of the participants (therapists $73 \%$, patients $67 \%(P=0.476))$ think that following an Ayurvedic lifestyle attitude is important, while $57 \%$ actually practice such a lifestyle (therapists $69 \%$, patients $46 \%(P=0.016))$. A majority of the respondents feel well acquainted with the concepts of reincarnation, karma, migration of the soul, nirvana, attachment, atman, brahman, enlightenment, and Buddhism. 30\% of the interviewees think that exact knowledge of the precise meaning of certain Ayurvedic Sanskrit terms is important, while $61 \%$ of the therapists assert that they actually have such knowledge. 54\% think that an Ayurvedic apprenticeship for European Ayurveda therapists should last at least 2 years.

Principal Component Analysis reduced the 12 variables in Table 4 to 3 different factors: (1) factor 1 comprises moksha, dharma, samkhya, vedanta, atman, brahman, and attachment; (2) factor 2 pulls together the concepts of nirvana, enlightenment, attachment, and karma; and (3) factor 3 correlates the concepts of reincarnation, karma, Buddhism, and transmigration of souls (Table 4).

3.5. Findings Related to Hypothesis 4. $76 \%$ of the participants are women; $65 \%$ of them are under 50 and above 30 years of age. Among women $65 \%$ identify themselves as Christian, among men $43 \%$. Gender differences can also be seen in the answer pattern for the question on whether Ayurveda is spirituality. $81 \%$ of women answered "yes," among men $46 \%$
TABLE 4: Factor analysis of participants' knowledge of key words of South Asian religion/spirituality.

\begin{tabular}{|c|c|c|c|}
\hline & \multicolumn{3}{|c|}{ Factor } \\
\hline & 1 & 2 & 3 \\
\hline $\begin{array}{l}\text { Are you familiar with the following term? } \\
\text { Moksha }\end{array}$ & 0.9 & & \\
\hline $\begin{array}{l}\text { Are you familiar with the following term? } \\
\text { Dharma }\end{array}$ & 0.9 & & \\
\hline $\begin{array}{l}\text { Are you familiar with the following term? } \\
\text { Samkhya }\end{array}$ & 0.8 & & \\
\hline $\begin{array}{l}\text { Are you familiar with the following term? } \\
\text { Vedanta }\end{array}$ & 0.8 & & \\
\hline $\begin{array}{l}\text { Are you familiar with the following term? } \\
\text { Atman/brahman }\end{array}$ & 0.7 & & \\
\hline $\begin{array}{l}\text { Are you familiar with the following term? } \\
\text { Nirvana }\end{array}$ & & 0.9 & \\
\hline $\begin{array}{l}\text { Are you familiar with the following term? } \\
\text { Enlightenment }\end{array}$ & & 0.8 & \\
\hline $\begin{array}{l}\text { Are you familiar with the following term? } \\
\text { Attachement }\end{array}$ & 0.5 & 0.7 & \\
\hline $\begin{array}{l}\text { Are you familiar with the following term? } \\
\text { Attachment }\end{array}$ & & & 0.9 \\
\hline $\begin{array}{l}\text { Are you familiar with the following term? } \\
\text { Karma }\end{array}$ & & 0.5 & 0.8 \\
\hline $\begin{array}{l}\text { Are you familiar with the following term? } \\
\text { Buddhism }\end{array}$ & & & 0.7 \\
\hline $\begin{array}{l}\text { Are you familiar with the following term? } \\
\text { Transmigration of the soul }\end{array}$ & & & 0.5 \\
\hline
\end{tabular}

Extraction method: Main Component Analysis. Rotation method: Varimax with Kaiser Normalization. (values $x$ are omitted, if $-0.5<x<0.5$ ).

$(P<0.001) .91 \%$ of the women who consider Ayurveda to be a philosophy also relate it to spirituality $(P<0.05) .74 \%$ of women think of Ayurveda as a dictum for life, among men only $58 \%$ ( $P=0.148) .50 \%$ of men, as compared to $35 \%$ of women, deny that Ayurveda is scientific in a modern western 
sense $(P=0.116) .86 \%$ of women think that Ayurvedic therapists should be trained by Ayurvedic experts from South Asia, among men $64 \%(P=0.103) .87 \%$ of women believe that Ayurvedic therapists should also have functions related to spirituality, as compared to $65 \%$ among men. $64 \%$ of the women think that therapists should sympathize with South Asian culture, religion, and philosophy as compared to $50 \%$ of men $(P=0.390) .73 \%$ of the women agree with the statement that a modern western medical education has no negative effects on the religious and spiritual characteristics of therapists, among men $59 \%(P=0.088) .79 \%$ of the women have been involved with rituals (men 66\%) and $72 \%$ with prayers (men 53\%). 85\% of the women believe in God, among men $58 \%(P=0.04) .71 \%$ of the women believe in angels, among men $45 \%(P<0.001) .64 \%$ of the male respondents and $44 \%$ of the female respondents find Christian religions lacking certain mystic perspectives which, for them, can be found in South Asian religions $(P=0.026) .50 \%$ of the men think that South Asian religions can offer better solutions to everyday contemporary problems than western religions, among women $43 \%(P=0.313)$. When questioned whether South Asian religions play a role for one's partner, $57 \%$ of men answered "yes," while $22 \%$ of women answered yes ( $P=$ 0.002).

\section{Discussion}

The metapostulate of this work was confirmed that individual sociocultural backgrounds, especially religious and spiritual ones, of Ayurvedic therapists and patients influence attitudes and expectations regarding Ayurvedic health care. Statistical relationships between individual religious and spiritual backgrounds and individual decisions to offer or access Ayurvedic services are clearly shown.

A statistically significant larger fraction of women in both groups is noticeable. Both therapists and patients also share an above average education. Results support the thesis that Ayurveda is being used by a predominantly well-educated, urban, and female clientele [76-78]. Differences with respect to income between groups suggest that hybrid forms of Ayurveda in the West are part of a "luxury" medicine; their usage is predominantly reserved for people with higher incomes (see Table 1) [79].

This survey investigates the perception of Ayurveda from a convenience sample of therapists and patients of predominantly western backgrounds. Therefore, it cannot define Ayurveda in any absolute term nor does it attempt to compare contemporary with "classic" Ayurvedic perspectives. Nevertheless the results of this survey point to a conception of Ayurveda as Whole Medical System, which also impacts the implementation of Ayurveda, particularly regarding the patient-doctor relationship [80, 81].

Individual forms of spirituality and religion seem to play a key role in the perception and definition of Ayurveda for patients and therapists. In our population adherers of Ayurveda have a tendency to have a special affinity for Buddhism, Hinduism, and South Asian culture in general. Christian religions (e.g., Protestant or Catholic churches) seem to play a less integral role in the practice and perception of Ayurveda, while "traditional" religious beliefs (e.g., a belief in god, angels, and the devil) can be grouped together with South Asian religious beliefs for a majority of the respondents (notably a belief in god, angels, and the devil can also be included in several South Asian belief systems as more recent texts include such concepts). Spirituality and religious aspects appear to be central in individual conceptions of salutogenesis $[82,83]$ and within the Ayurvedic therapeutic paradigm [84]. Thereby spirituality, not religion, is the preferred self-categorization within the field of Ayurveda. The results pose the question whether individual references to traditional Christian values might have become weaker due to a loss of confidence in established western religious institutions $[85,86]$. These values may thus be substituted or supplemented by the individually composed syncretistic realities of patients and therapists using or offering Ayurveda (e.g., combining god, karma, and nirvana), whose religious and spiritual impulses continue to guide them [87].

While both therapists and patients are engaged with religious and spiritual questions and are open to these issues, therapists seem to deal even more with religious and spiritual matters than their patients. Beyond pure somatic healthcare services, adherents of Ayurveda expect the therapist to also function as a spiritual/psychological caregiver. As a result of training and patient expectations, the Ayurvedic therapist also frequently engages in functions (within an Ayurvedic treatment) that are also characterized by religious and spiritual elements, for example, mantra recitation, performing rituals, meditation, prayers, and so forth [88].

Our data support the hypothesis that elements from South Asian culture, religion, and philosophy seem to play an important role for Ayurvedic patients and therapists. A high level of "authenticity" and "authentic therapy" is expected from the therapists and therapies. It is notable that not only therapists but also patients seem to be quite well versed in South Asian culture, religion, and philosophy. This suggests that the choice for Ayurveda might go hand in hand with a fundamental affinity to South Asian culture and worldview [89].

For Ayurvedic patients and therapists, spirituality, religion, and principles of modern science are not in conflict. For them, Ayurveda contains aspects of spirituality, religion, and science at the same time. While spirituality is seen as a very important aspect, which also influences the daily life of therapists and patients, the medical dimension of Ayurveda is still seen as the most important one and does not exclude the simultaneous use of modern medicine for the majority. The composition of Ayurvedic characteristics that is expected from the majority of those participants could be interpreted as a curiosity for novel things and at the same time as an expression of uncertainty and discontent with prevailing structures. Frustration with modern medicine is less important in the decision to use Ayurveda than, for example, the inclusion of the spiritual dimension. An "enchantment of the world," a concept often mentioned in CAM contexts, is supposed to help overcome the separation of matter, mind, and soul. Next to scientific knowledge, spirituality stands on equal footing. Religion in a classical sense seems to take a back seat in favour of spirituality. However, this is to a certain 
degree a tenuous position based on the factor analyses related to the second hypothesis of this work.

In our survey Ayurveda is used-as is CAM in general in the western world-by a well-educated, middle class, and female dominated clientele $[90,91]$. Women access Ayurveda more often than men among the surveyed participants, and women appear to be more open to religious and spiritual matters [26]. Almost all characteristics related to religiosity and spiritual attitudes are more prominently represented among women in our data set [92].

Ayurveda patients and therapists seem to be more open to CAM, especially nonwestern CAM methods, but this does not exclude the simultaneous use of modern western medicine for the majority of respondents. Moreover, Ayurveda may be compensating for deficits in the field of psychosocial healthcare logistics $[93,94]$. In this conception the Ayurvedic therapist does more than simply treat somatic disorders. Ayurvedic concepts are based on anthropologic/cosmological assumptions which include different levels of human existence in both diagnostic and therapeutic healing approaches. As a result, therapist-patient relationships focused on the individual's unique experience and promoting trust and confidential discussion of spiritual matters in the therapeutic encounter are accommodated and indeed cultivated.

There are several limitations of this work. This study was informed by a small sample size rather than a large scale inquiry; thus various nonspecific effects, for example, the inhomogeneous settings, may have contributed to the answer patterns and thus may have significantly biased the results. Further a statistically significant larger fraction of women in both groups is noticeable (which however also reflects the field). Moreover, the partial reporting of the results as pooled data from patients and therapists may bias the picture depending on potentially different attitudes and knowledge about Ayurveda via patients versus therapists. The fact that $15 \%$ of patients are also trained as Ayurvedic therapists is a further limitation and a potential source of bias. Another issue may be that the potential simultaneous use of other CAM methods was not assessed by the questionnaire. Another minor limitation is the fact that some of the used items may have had influencing or directing effects due to their wording or an intentional open phrasing. It is also important to keep in mind while interpreting the results that this not a representative population sample but a sample that was likely to be prone to Ayurveda, which of course is another limitation of this study.

To summarize, key questions regarding the character, essence, complexity, and contextualization of Ayurveda in its original and hybrid forms remain largely unanswered. The following questions yet to be answered seem to be of high exigency. (a) What is Ayurveda in general and can a clear definition of it be given independently of western or Indian contexts? (b) What are the reasons for choosing Ayurveda out of a range of different methods of CAM and is the choice for Ayurveda specific or random? (c) What exactly does "spirituality" mean for therapists and patients in the case of Ayurveda? Overall, normative questions about whether Ayurveda is a science or religion or spirituality seem to be deceptive. It might also be helpful to move away from asking whether and to what extent Ayurveda acts in this context and to instead focus more on why and how it functions in association with science, religion, and spirituality. Let us keep in mind that these concepts are not natural entities. Religion, spirituality, and science are modern western concepts and have a strong potential to export normative and ideological items into what are primarily nonwestern contexts $[17,95-$ 97].

Looking at Ayurveda as a whole medical system including physical, psychological, medical, and spiritual elements, as well as a philosophy and a way of life, may challenge the differentiation, compartmentalization, and rationalization of modern societies [98-100], while leading to a better understanding of Ayurveda as an expression of and complement to "modern western medicine."

Given the complexity of the topic and the exploratory nature of the survey, larger surveys with fully validated questionnaires, preceding qualitative phases, and refined hypotheses are warranted to support the results of this first pilot survey.

\section{Conflict of Interests}

There are no financial or nonfinancial competing interests to be declared in relation to this paper by any of the authors.

\section{Authors' Contribution}

C. Kessler carried out development, design, and implementation of the survey. M. Wischnewsky participated in the design of the survey and performed the statistical analysis. A. Michalsen, C. Eisenmann, and J. Melzer took part in drafting the paper. All authors read and approved the final paper.

\section{Acknowledgment}

We would cordially like to thank Kenneth Spiteri and Jennifer Rioux for their language assistance and, most of all, Thomas Oberlies for making this project possible.

\section{References}

[1] M. Monier-Williams, A Sanskrit English Dictionary: Ayurveda, Motilal Banar-sidass, Delhi, Indian, 2002, Corrected Edition.

[2] C. Kessler and A. Michalsen, "The role of whole medical systems in global medicine," Forsch Komplementmed, vol. 19, pp. 65-66, 2012.

[3] C. M. Witt, A. Michalsen, S. Roll et al., "Comparative effectiveness of a complex ayurvedic treatment and conventional standard care in osteoarthritis of the knee-study protocol for a randomized controlled trial," Trials, vol. 14, no. 1, article 149, 2013.

[4] F. Capra, The Web of Life: A New Scientific Understanding of Living Systems, Anchor Books, New York, NY, USA, 1996.

[5] I. R. Bell and M. Koithan, "Models for the study of whole systems," Integrative Cancer Therapies, vol. 5, no. 4, pp. 293-307, 2006. 
[6] WHO, Traditional Medicine, Report by the Secretariat, A 56/18, World Health Organization, Geneva, Switzerland, 2003.

[7] G. J. Meulenbeld, A History of Indian Medical Literature, vol. 5, Egbert Forsten, Groningen, The Netherlands, 1999.

[8] R. K. Sharma and B. Dash, Text with English Translation and Critical Exposition Based on Cakrapani Datta's Ayurveda Dipika, vol. 7, Chaukhamba, New Delhi, India, 2001, edited by C. Samhita.

[9] S. E. Yukti, "Die Caraka Samhitā und die Rationalität ihres therapeutischen Ansatzes," Magisterarbeit der Fakultät Kulturwissenschaften der Universität Tübingen, 1997.

[10] WHO, Traditional Medicine in Asia, World Health Organization Regional, New Delhi, India, 2002.

[11] C. Kessler, Wirksamkeit Von Ayurveda Bei chronische Erkrankungen: Systematische Analysen Klinischer Ayurveda-Studien, KVC, Essen, Germany, 2007.

[12] Association of Ayurvedic Physicians of India (AAPI), 2013, http://aapiindia.org/.

[13] WHO, Benchmarks for Training in Traditional/Complementary and Alternative Medicine: Bench-Marks for Training in Ayurveda, World Health Organization, Geneva, Switzerland, 2010.

[14] A. Morandi, C. Tosto, P. Roberti di Sarsina, and D. D. Libera, "Salutogenesis and Ayurveda: indications for public health management," The EPMA Journal, vol. 2, no. 4, pp. 459-465, 2011.

[15] S. N. Gupta and E. Stapelfeld, Praxis in der Ayurveda-Medizin: Kaya-Cikitsa-Therapiekonzepte für Innere Erkrankungen, Haug, Stuttgart, Germany, 2009.

[16] S. Engler, "Science' vs. "religion" in classical Ayurveda," in Numen, vol. 50, Koninklijke Brill NV, Leiden, The Netherlands, 2003.

[17] R. P. Das, "Indische medizin und spiritualität," Journal of the European Ayurvedic Society, vol. 2, pp. 158-187, 1992.

[18] Institut für Demoskopie Allensbach, Naturheilmittel. Ergebnisse einer bevölkerungsrepräsentativen Befragung, 2011, http:// www.pandalis.de/en.

[19] Google-Website Search term: Ayurveda. 2012, https://www .google.de/.

[20] DÄGAM-Website, February 2012, http://www.daegam.de/.

[21] E. Durkheim, Die Elementaren Formen des ReligiöSen Lebens, Suhrkamp, Frankfurt, Germany, 1997.

[22] R. Sponsel, "Spiritualität. Eine psychologische Untersuchung," Publikation für Allgemeine und Integrative Psychotherapie 2008, http://www.sgipt.org/wisms/gb/spirit0.htm.

[23] M. Verhoef, M. Koithan, I. R. Bell, J. Ives, and W. Jonas, "Whole complementary and alternative medical systems and complexity: creating collaborative relationships," Forschende Komplementarmedizin, vol. 19, supplement 1, pp. 3-6, 2012.

[24] F. Capra, The Web of Life: A New Scientific Understanding of Living Systems, Anchor Books, New York, NY, USA, 1996.

[25] E. Laszlo, "The meaning and significance of general system theory," Behavioral Science, vol. 20, no. 1, pp. 9-24, 1975.

[26] B. J. West, Where Medicine Went Wrong, World Scientific, River Edge, NJ, USA, 2006.

[27] S. B. Frampton and S. Guastello, "Putting patients first: patientcentered care: more than the sum of its parts," American Journal of Nursing, vol. 110, no. 9, pp. 49-53, 2010.

[28] I. R. Bell and M. Koithan, "Models for the study of whole systems," Integrative Cancer Therapies, vol. 5, no. 4, pp. 293-307, 2006.
[29] C. Elder, M. Aickin, I. R. Bell et al., "Methodological challenges in whole systems research," Journal of Alternative and Complementary Medicine, vol. 12, no. 9, pp. 843-850, 2006.

[30] PubMed, Bethesda: National Center for Biotechnology Information, U.S. National Library of Medicine. Search term: Ayurved. 2012, http://www.ncbi.nlm.nih.gov/pubmed/.

[31] DHARA, Tamil Nadu: AVT Institute for Advanced Research, http://www.dharaonline.org.

[32] A. Koch, "Wie medizin und heilsein wieder verwischen. Ethische plausibilierungsmuster des Ayurveda im Westen," Zeitschrift Für Medizinische Ethik, vol. 52, no. 2, pp. 169-182, 2006.

[33] R. Frank, Globalisierung und Kontextualisierung Heterodoxer Medizin, Transcript, Bielefeld, Germany, 2004.

[34] G. Stollberg, "Asian medical concepts in Germany and the United Kingdom: sociological reflections on the shaping of Ayurveda in Western Europe," Traditional South Asian Medicine, vol. 6, pp. 3-9, 2001.

[35] G. Stollberg and R. Frank, "Countervailing creativity: the globalisation of Asian medicines, patient perspectives," in Ayurvedic Patients in Germany, E. Hsu and E. Hoeg, Eds., vol. 9, pp. 223244, 2002.

[36] L. N. Ravindran and A. V. Ravindran, "Spirituality and mental health-reflections of the past, application in the present and projections for the future," in Neurobiology of Spirituality: A Brief Review, A. Sharma and N. Patel, Eds., pp. 531-551, Om Shanit Press, Mount Abu, India, 2009.

[37] C. Klein, H. Berth, and F. Balck, Gesundheit-Religion -Spiritualität. Konzepte, Befunde und Erklärungsansätze, Juventa, Weinheim und München, 2011.

[38] S. Donnelly, L. Rybicki, and D. Walsh, "Quality of life measurement in the palliative management of advanced cancer," Supportive Care in Cancer, vol. 9, no. 5, pp. 361-365, 2001.

[39] S. M. Skevington, K. S. Gunson, and K. A. O 'Connell, "Introducing the WHOQOL-SRPB BREF: developing a short-form instrument for assessing spiritual, religious and personal beliefs within quality of life," Quality of Life Research 2012. In press.

[40] I. Chopra and K. M. Kamal, "A systematic review of quality of life instruments in long-term breast cancer survivors," Health and Quality of Life Outcomes, vol. 10, article 14, 2012.

[41] M. Adegbola, "Spirituality self-efficacy, and quality of life among adults with sickle cell disease," South Online Journal of Nursing Research, vol. 11, no. 1, article 5, 2011.

[42] S. J. Bartlett, R. Piedmont, A. Bilderback, A. K. Matsumoto, and J. M. Bathon, "Spirituality, well-being, and quality of life in people with rheumatoid arthritis," Arthritis Care and Research, vol. 49, no. 6, pp. 778-783, 2003.

[43] M. J. Brady, A. H. Peterman, G. Fitchett, M. Mo, and D. Cella, "A case for including spirituality in quality of life measurement in oncology," Psycho-Oncology, vol. 8, no. 5, pp. 417-428, 1999.

[44] K.-K. Leung, T.-Y. Chiu, and C.-Y. Chen, "The influence of awareness of terminal condition on spiritual well-being in terminal cancer patients," Journal of Pain and Symptom Management, vol. 31, no. 5, pp. 449-456, 2006.

[45] L. J. Kirmayer, "The cultural diversity of healing: meaning, metaphor and mechanism," British Medical Bulletin, vol. 69, pp. 33-48, 2004.

[46] T. J. Kaptchuk and D. M. Eisenberg, "Varieties of healing. 1: medical pluralism in the United States," Annals of Internal Medicine, vol. 135, no. 3, pp. 189-195, 2001.

[47] A. Büssing, T. Ostermann, and P. F. Matthiessen, "Distinct expressions of vital spirituality: the ASP questionnaire as 
an explorative research tool," Journal of Religion and Health, vol. 46, no. 2, pp. 267-286, 2007.

[48] E. Ben-Arye, E. Schiff, H. Vintal, O. Agour, L. Preis, and M. Steiner, "Integrating complementary medicine and supportive care: patients' perspectives toward complementary medicine and spirituality," The Journal of Alternative and Complementary Medicine, vol. 18, no. 9, pp. 824-831, 2012.

[49] D. E. Furst, M. M. Venkatraman, M. Mcgann et al., "Doubleblind, randomized, controlled, pilot study comparing classic ayurvedic medicine, methotrexate, and their combination in rheumatoid arthritis," Journal of Clinical Rheumatology, vol. 17, no. 4, pp. 185-192, 2011.

[50] R. P. Stanard, D. S. Sandhu, and L. C. Painter, "Assessment of spirituality in counseling," Journal of Counseling and Development, vol. 78, no. 2, pp. 204-210, 2000.

[51] W. R. Miller and C. E. Thoresen, "Spirituality, religion, and health: an emerging research field," American Psychologist, vol. 58, no. 1, pp. 24-35, 2003.

[52] N. Egbert, J. Mickley, and H. Coeling, "A review and application of social scientific measures of religiosity and spirituality: assessing a missing component in health communication research," Health Communication, vol. 16, no. 1, pp. 7-27, 2004.

[53] D. Sackett, S. Strauss, W. Richardson, W. Rosenberg, and R. Haynes, Evidence-Based Medicine. How to Practice and Teach $E B M$, Churchill Livingstone, New York, NY, USA, 2nd edition, 2000.

[54] P. G. Reed, "Developmental resources and depression in the elderly: a longitudinal study," Nursing Research, vol. 35, no. 6, pp. 368-374, 1986.

[55] P. G. Reed, "Religiousness among terminally ill and healthy adults," Research in Nursing \& Health, vol. 9, no. 1, pp. 35-41, 1986.

[56] M. J. Atkinson, P. M. Wishart, B. I. Wasil, and J. W. Robinson, "The self-perception and relationships tool (S-PRT): a novel approach to the measurement of subjective health-related quality of life," Health and Quality of Life Outcomes, vol. 2, article 36, 2004.

[57] A. H. Peterman, G. Fitchett, M. J. Brady, L. Hernandez, and D. Cella, "Measuring spiritual well-being in people with cancer: the functional assessment of chronic illness therapy-spiritual well-being scale (FACIT-Sp)," Annals of Behavioral Medicine, vol. 24, no. 1, pp. 49-58, 2002.

[58] M. F. Ledbetter, L. A. Smith, J. D. Fischer, and W. L. VoslerHunter, "An evaluation of the research and clinical usefulness of the spiritual well-being scale," Journal of Psychology and Theology, vol. 19, pp. 49-55, 1991.

[59] A. Büssing, T. Ostermann, and P. F. Matthiessen, "Distinct expressions of vital spirituality: the ASP questionnaire as an explorative research tool," Journal of Religion and Health, vol. 46, no. 2, pp. 267-286, 2007.

[60] A. Büssing, P. F. Matthiessen, and T. Ostermann, "Engagement of patients in religious and spiritual practices: confirmatory results with the SpREUK-P 1.1 questionnaire as a tool of quality of life research," Health and Quality of Life Outcomes, vol. 3, article 53, 2005.

[61] D. B. Creel, "Assessing the influence of religion on health behavior, Dissertation Indiana University, 2007, http://etd.lsu.edu/ docs/available/etd-05162007-090802/unrestricted/Creel_dis .pdf.

[62] D. O. Moberg, "Assessing and measuring spirituality: confronting dilemmas of universal and particular evaluative criteria," Journal of Adult Development, vol. 9, no. 1, pp. 47-60, 2002.
[63] D. A. MacDonald, H. L. Friedman, and J. G. Kuentzel, "A survey of measures of spiritual and transpersonal constructs: part one-research update," Journal of Transpersonal Psychology, vol. 31, no. 1, pp. 137-154, 1999.

[64] D. A. MacDonald, J. G. Kuentzel, and H. L. Friedman, "A survey of measures of spiritual and transpersonal constructs: part two-additional instruments," Journal of Transpersonal Psychology, vol. 31, pp. 137-178, 1999.

[65] E. L. Idler, M. A. Musick, C. G. Ellison et al., "Measuring multiple dimensions of religion and spirituality for health research: conceptual background and findings from the 1998 general social survey," Research on Aging, vol. 25, no. 4, pp. 327-365, 2003.

[66] J. D. Kass, R. Friedman, J. Leserman, P. C. Zuttermeister, and H. Benson, "Health outcomes and a new index of spiritual experience," Journal for the Scientific Study of Religion, vol. 30, no. 2, pp. 203-211, 1991.

[67] P. C. Hill, "Measurement in the psychology of religion and spirituality, current status and evaluation," in Handbook of the Psychology of Religion and Spirituality, R. F. Paloutzian and C. L. Park, Eds., pp. 43-61, The Guilford Press, London, UK, 2005.

[68] Fetzer Institute, "Multidimensional measurement of religiousness/spirituality for use in health research," A report of the Fetzer Institute/National Institute on Aging Working Group, Fetzer Institute, Kalamazoo, Mich, USA, 1999.

[69] J. W. Berry, "Imposed etics-emics-derived etics: the operationalization of a compelling Idea," International Journal of Psychology, vol. 24, no. 6, pp. 721-735, 1989.

[70] J. W. Berry, "Emics and etics: a symbiotic conception," Culture and Psychology, vol. 5, no. 2, pp. 165-171, 1999.

[71] H. Knoblauch, "Soziologie der spiritualität," in Handbuch Spiritualität, K. Baier, Ed., pp. 91-111, Wissenschaftliche Buchgesellschaft, Darmstadt, Germany, 2006.

[72] C. B. Terwee, S. D. M. Bot, M. R. de Boer et al., "Quality criteria were proposed for measurement properties of health status questionnaires," Journal of Clinical Epidemiology, vol. 60, no. 1, pp. 34-42, 2007.

[73] J. Olsen, "Epidemiology deserves better questionnaires," International Journal of Epidemiology, vol. 27, no. 6, p. 935, 1998.

[74] K. A. Yeomans and P. A. Golder, "The guttman-kaiser criterion as a predictor of the number of common f actors," Journal of the Royal Statistical Society D, vol. 31, no. 3, pp. 221-229, 1982.

[75] K. Backhaus, B. Erichson, W. Plinke, and R. Weiber, Multivariate Analysemethoden: Eine Anwendungsorientierte EinfüHrung, Springer, Berlin, Heidelberg, Germany, 9th edition, 2000.

[76] P. Kaiser, Arzt und Guru-die Suche Nach dem Richtigen Therapeuten in der Postmoderne, Diagonal, Marburg, Germany, 2001.

[77] L. Conboy, S. Patel, T. J. Kaptchuk, B. Gottlieb, D. Eisenberg, and D. Acevedo-Garcia, "Sociodemographic determinants of the utilization of specific types of complementary and alternative medicine: an analysis based on a nationally representative survey sample," Journal of Alternative and Complementary Medicine, vol. 11, no. 6, pp. 977-994, 2005.

[78] W. B. Jonas, D. Eisenberg, D. Hufford, and C. Crawford, “The evolution of complementary and alternative medicine (CAM) in the USA over the last 20 years," Forsch Komplementmed, vol. 20, no. 1, pp. 65-72, 2013.

[79] P. Bagla, "Piercing the veil of Ayurveda," Science, vol. 334, no. 6062, p. 1491, 2011.

[80] R. van Haselen and R. Jütte, "The placebo effect and its ramifications for clinical practice and research. Villa la collina at 
lake como, Italy, 4-6 May 2012," Complementary Therapies in Medicine, vol. 21, no. 2, pp. 85-93, 2013.

[81] R. N. Turner, J. Leach, and D. Robinson, "First impressions in complementary practice: the importance of environment, dress and address to the therapeutic relationship," Complementary Therapies in Clinical Practice, vol. 13, no. 2, pp. 102-109, 2007.

[82] A. Antonovsky, Health, Stress and Coping, Jossey-Bass, San Francisco, Calif, USA, 1979.

[83] A. Antonovsky, Unraveling the Mystery of Health-How People Manage Stress and Stay Well, Jossey-Bass, San Francisco, Calif, USA, 1987.

[84] A. Morandi, C. Tosto, P. Roberti di Sarsina, and D. D. Libera, "Salutogenesis and Ayurveda: indications for public health management," EPMA Journal, vol. 2, no. 4, pp. 459-465, 2011.

[85] S. Geisler, "Spiritualität in der medizin arznei-placebodroge?” Universitas, vol. 6, pp. 132-143, 2006.

[86] P. Heelas and L. Woodhead, The Spiritual Revolution. Why Religion Is Giving Way to Spirituality, Wiley-Blackwell, Malden, Mass, USA, 2005.

[87] M. Warrier, "Seekership, spirituality and self-discovery: Ayurveda trainees in Britain," Asian Medicine, vol. 4, no. 2, pp. 423451, 2009.

[88] S. Chattopadhyay, "Religion, spirituality, health and medicine: why should Indian physicians care?" Journal of Postgraduate Medicine, vol. 53, no. 4, pp. 262-266, 2007.

[89] V. B. Gupta, "Impact of culture on healthcare seeking behavior of Asian Indians," Journal of Cultural Diversity, vol. 17, no. 1, pp. 13-19, 2010.

[90] D. M. Eisenberg, R. B. Davis, S. L. Ettner et al., "Trends in alternative medicine use in the United States, 1990-1997: results of a follow-up national survey," Journal of the American Medical Association, vol. 280, no. 18, pp. 1569-1575, 1998.

[91] Cambrella, "Complementary and Alternative Medicine (CAM plays an important role in healthcare in Europe-but too little is known about it)," 2013, http://www.cambrella.eu/home.php.

[92] H. Knoblauch, Populäre Religion: Auf dem Weg in eine Spirituelle Gesellschaft, Campus, New York, NY, USA, 2009.

[93] W. Andritzky, "Alternative gesundheitskultur: medizinanthropologische perspektiven und ergebnisse sozialwissenschaftlicher Studien," in Jahrbuch für Transkulturelle Medizin und Psychotherapie, für Wissenschaft und Bildung, Berlin, Germany, 1992.

[94] M. Stöhr, Ärzte, Heiler, Scharlatane. Schulmedizin und Alternative Heilverfahren Auf dem Prüfstand, Steinkopff, Heidelberg, Germany, 2001.

[95] G. R. Peterson, "Going public: science-and-religion at a crossroads," Zygon, vol. 35, no. 1, pp. 13-24, 2000.

[96] H. Selin, Ed., Encyclopaedia of the History of Science, Technology, and Medicine in Non-Western Cultures, Kluwer, Dordrecht, The Netherlands, 1997, edited by H. Selin.

[97] S. Goonatilake, "The voyages of discovery and the loss and rediscovery of 'others' knowledge," Impact of Science on Society, vol. 167, pp. 241-264, 1992.

[98] M. Weber, Gesammelte Aufsätze Zur Religionssoziologie, Band I. Tübingen Mohr Siebeck, Tuebingen, Germany, 1920.

[99] P. Berger, B. Berger, and H. Kellner, Das Unbehagen in der Modernität, Campus, New York, NY, USA, 1987.

[100] U. Karstein and F. Benthaus-Apel, "Asien als Alternative oder Kompensation? Spirituelle Körperpraktiken und ihr transformatives Potential (nicht nur) für das religiöse Feld," in Körper,
Sport Und Religion, R. Gugutzer and M. Böttcher, Eds., pp. 311339, Springer, 2012. 


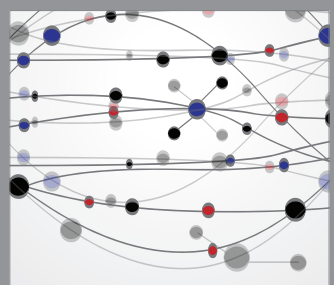

The Scientific World Journal
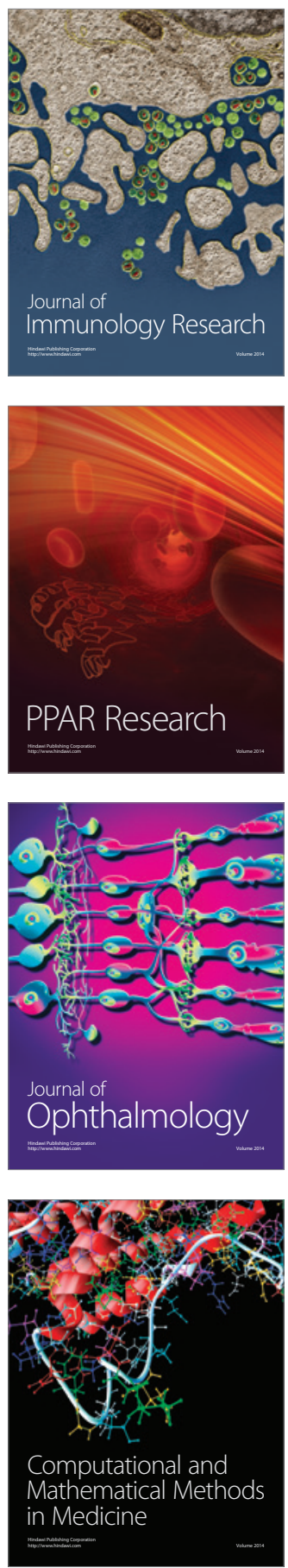

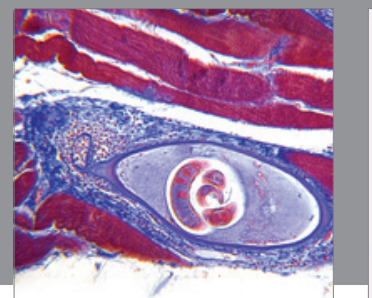

Gastroenterology

Research and Practice
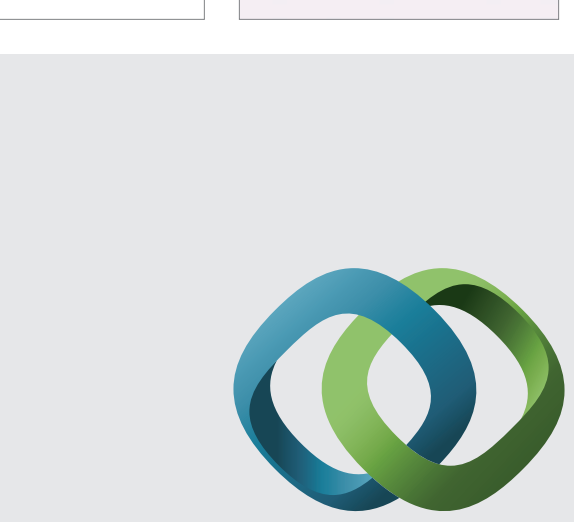

\section{Hindawi}

Submit your manuscripts at

http://www.hindawi.com
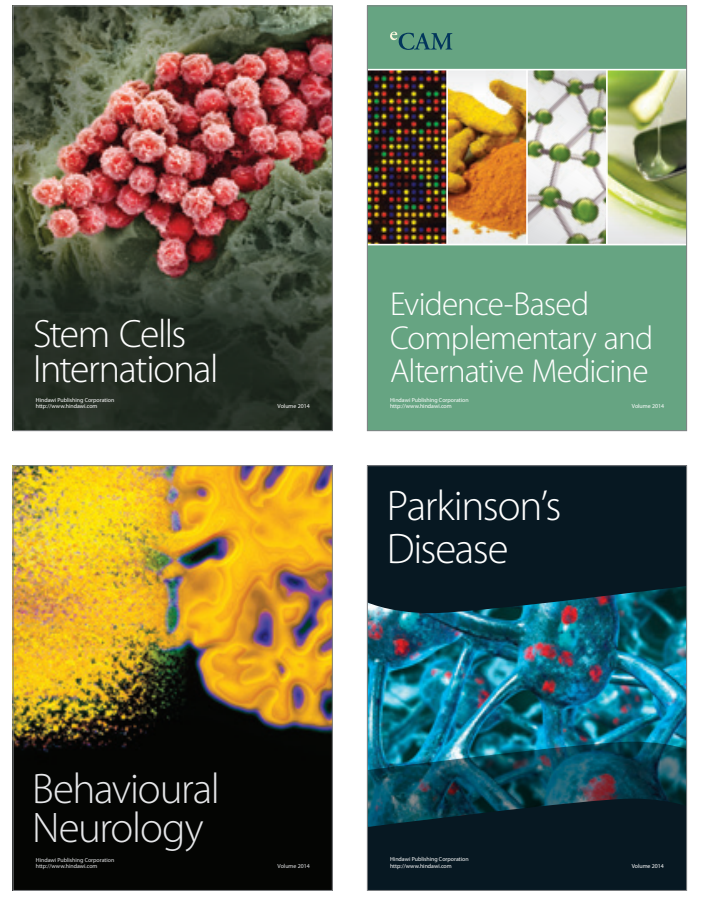
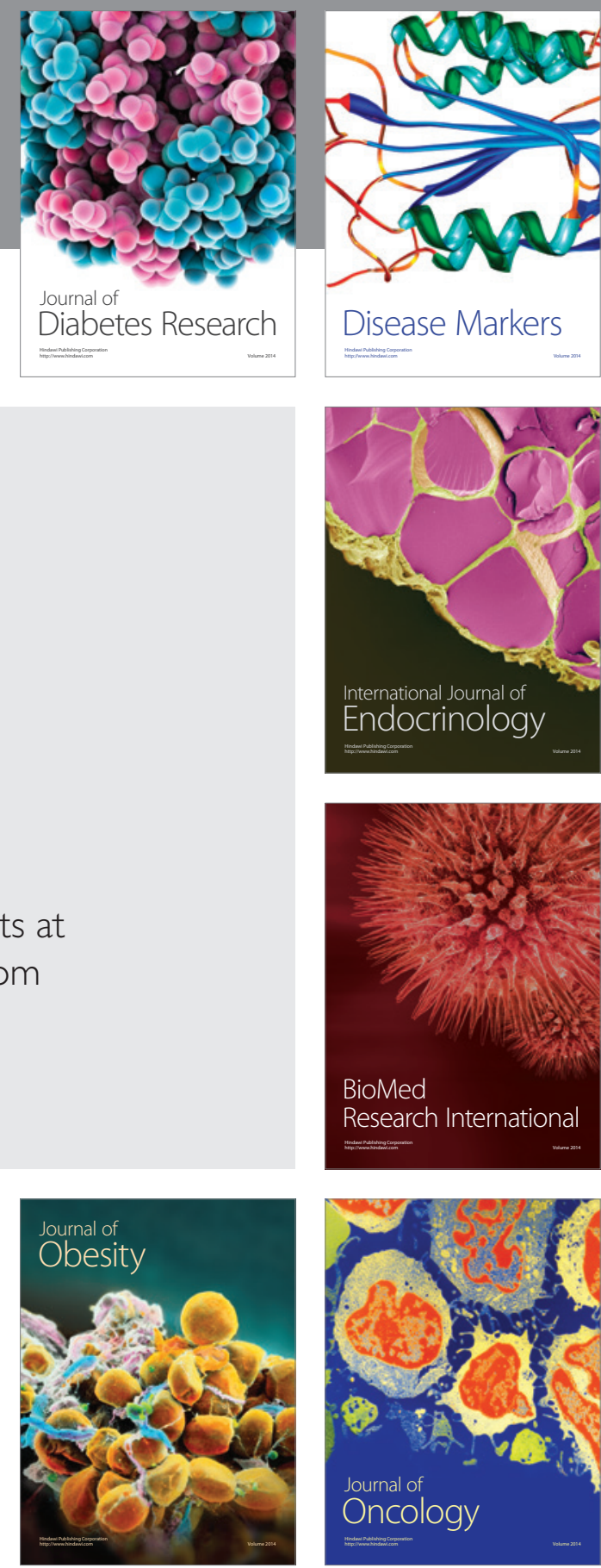

Disease Markers
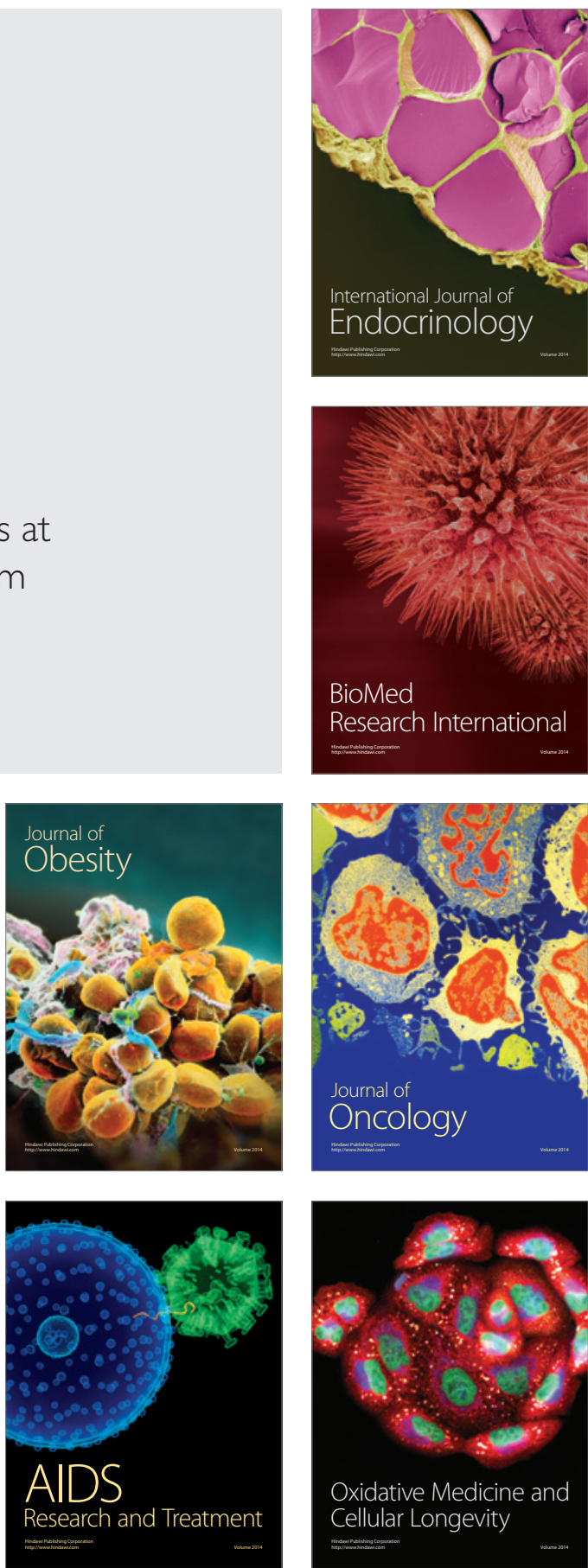